
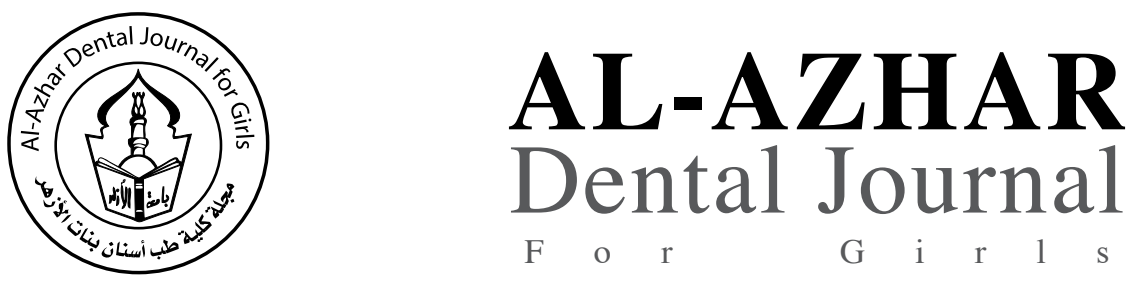

The Official Publication of The Faculty of Dental Medicine For Girls, Al-Azhar University Cairo, Egypt.

ADJ-for Grils, Vol. 4, No. 1, January (2017) — PP. 9:12

\title{
Effect of Topically- Applied Hyaluronan on the Expression of Prolyl 4- Hydroxylase in Gingivitis of Diabetic Rats
}

\author{
Rawand Samy Abu Nahla ${ }^{(1)}$, Marwa -El Sheikh ${ }^{(1)}$ and Abeer Gawish
}

Codex : 02/1701

dentaljournal.forgirls@yahoo.com

\begin{abstract}
Objective: To evaluate the effect of topically applied hyaluronic acid gel (hyaluranon) on gingivitis in diabetic rats. The evaluation based on clinical, histological, and immunohistochemical analysis.

Materials and Methods: The present study included seventy rats were included in this study, sixty rats were divided into two main groups according to treatment modality, group I involved thirty rats treated with topical HA, while group II involved thirty rats left untreated. Furthermore groups I and II subdivided into subgroups Ia, IIa were sacrificed on the seventh day, and subgroups Ib, IIb were sacrificed was sacrificed on the day fourteen, negative control compromised five healthy rats, and positive control group compromised five diabetic rats. Harvested gingival specimens were fixed in formalin, then embedded in paraffin wax, and serially sectioned at $4 \mu \mathrm{m}$ for immunohistochemical assessment using Prolyl 4 Hydroxylase A1(P4HA1). Results: Immunohistochemical evaluation using $\mathrm{P} 4 \mathrm{HA} 1$ revealed a significant difference between all groups.
\end{abstract}

\section{INTRODUCTION}

Gingivitis and periodontitis are chronic inflammatory diseases of the underlying and surrounding tooth tissues. The initial factor is the microbial stimuli which stimulate the host response and its defense capacity to; systemic factors modify all forms of gingivitis and periodontitis through their effect on physiological immune and inflammatory defense ${ }^{(1)}$.

1. Lecturer Assistant of Oral Medicine, Periodontology, Oral Diagnosis and Radiology Department. Faculty of Dental Medicine Alazhar University Palestine.

2. Lecturer of Oral Biology Department. Faculty of Dental Medicine for Girls. Alazhar University.

3. Proffessor of Oral medicine,Periodontology, Oral Diagnosis and Radiology Department. Faculty of Dental Medicine for Girls. Alazhar University 
Diabetes Mellitus (DM) is agroup of metabolic disorder manifested by abnormally high-level of glucose. The hyperglycemic state developed from either a deficiency in insulin secretion or an impaired cellular resistance to the action of insulin and it is associated with a number of complications, such as retinopathy, neuropathy,_nephropathy, angiopathy, atherosclerosis, impaired wound healing, and periodontal disease ${ }^{(2,3)}$. DM has been shown to alter collagen metabolism in gingiva, bone and basement membrane, impair immune mechanism and varies functions of the polymorphonuclear leukocyte including its chemotactic, phagocytic, microbiocidal and collagenolytic activities ${ }^{(4)}$.

Hyluronic acid (HA) is a natural substance; it is a major part of tissue ground substance in which cells of the body grow. It is a polymer of glucoronic acid and glucosamine. It is the most common substances known as glycosaminoglycans, which form the glue like extracellular matrix of connective tissue ${ }^{(5)}$ (Bartold, 1988).

Prolyl 4 hydroxylases (P4Hs) is an essential enzyme in the biosynthesis and folding of newlysynthesized collagen polypeptide chains into triplehelical molecules. The expression of the subunit of $\mathrm{P} 4 \mathrm{Hs}$ limits the rate of active $\mathrm{P} 4 \mathrm{H}$ formation, $\mathrm{P} 4 \mathrm{H}$ activity, and collagen synthesis ${ }^{(6)}$.

\section{MATERIALS AND METHODS}

Seventy rats were included in this study, sixty rats were divided into two main groups according to treatment modality, group I involved thirty rats with gingivitis, DM and treated with topical HA, while group II involved thirty rats with gingivitis, DM and left untreated. Furthermore group I divided into two groups group Ia was sacrificed on the seventh day, group Ib which compromised fifteen rats was sacrificed on the day fourteen, Furthermore group II which involved thirty rats with gingivitis and DM divided into two groups group IIa which was sacrificed after 7 days, group II b which was sacrificed after 14 days, negative control group was compromised five normal healthy rats, positive control group was compromised five diabetic rats with gingivitis and was sacrificed after 14 days ${ }^{(7)}$.

Induction of Diabetes Mellitus: The selected animals were administered with a single intraperitoneal dose $(50 \mathrm{mg} / \mathrm{kg})$ of streptozotocin.

Induction of gingivitis: Diabetic rats were anaesthetized and ligature (3-0 silk) were placed around the cervices of the mandibular incisors ${ }^{(8)}$, maxillary second molar ${ }^{(9)}$.Experimental gingivitis was established after 7 to14 days, group II rats were sacrificed on the $14^{\text {th }}$ day ${ }^{(10)}$.

Treatment: Topically applied HA $0.8 \%$ was used twice per aday for treatment of gingivitis in Group I which compromised thirty diabetic rats with gingivitis.

Animal Scarification: Rats were sacrificed by overdose of carbon dioxide inhalation. The gingiva of upper second molar and lower incisors regions of the sacrificed animals was extracted for histological examination and immunohistochemical analysis ${ }^{(11)}$.

Immunohistochemical analysis: Using anti Prolyl 4 Hydroxylase.

\section{Statistical Analysis}

Unpaired $t$ test was used for comparison between each 2 groups. ANOVA test was used to compare all groups, and then Tukey's post hoc test was used for pairwise comparison between groups.

\section{RESULTS}

Immunohistochemical assessment: showed that group $\mathrm{Ib}$ which represented diabetes with induced gingivitis, and treated with HA gel $0.8 \%$ for 14 days, with strong positive localized intracellular expression of P4HA1 is begin to appear at basal cell layer and strong positive generalized intracellular expression of P4HA1 in at prickle cell layer, while it showed very weak positive localized intracellular 
expression of P4HA1, at granular cell layers and superficial cornified cell layers (Figure.1).

\section{Results of Immunohistomorphic Analysis: Comparison of area percent of immunoexpression in all groups:}

Table (1): Mean and standard deviation of area percent of immunoexpression in all groups and significance of the difference using ANOVA test.

\begin{tabular}{|c|c|c|c|c|c|c|}
\hline & $\begin{array}{c}\text { Negative } \\
\text { control }\end{array}$ & $\begin{array}{c}\text { Positive } \\
\text { control }\end{array}$ & $\begin{array}{c}\text { Group } \\
\text { I a }\end{array}$ & $\begin{array}{c}\text { Group } \\
\text { IIa }\end{array}$ & $\begin{array}{c}\text { Group } \\
\text { Ib }\end{array}$ & $\begin{array}{c}\text { Group } \\
\text { II b }\end{array}$ \\
\hline Mean & $7.189^{\mathrm{b}}$ & $12.298^{\mathrm{a}}$ & $2.689^{\mathrm{e}}$ & $6.88^{\mathrm{b}}$ & $5.371^{\mathrm{c}}$ & $4.416^{\mathrm{d}}$ \\
\hline Std Dev & 1.444 & 1.672 & 0.831 & 1.478 & 1.013 & 1.005 \\
\hline F value & \multicolumn{7}{|c|}{43.78} \\
\hline P value & \multicolumn{7}{|c|}{$<0.00001^{*}$} \\
\hline
\end{tabular}

*significant at $p<0.05$

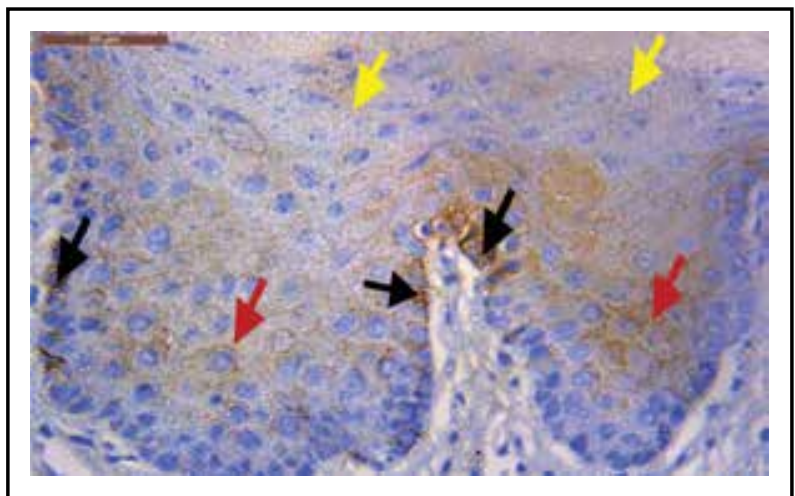

Fig. (1): A photomicrograph of group Ib showing strong positive localized intracellular expression P4HA1 in some areas at basal cell layer (black arrows), strong positive generalized intracellular expression of P4HA1 in prickle cell layer (red arrows), weak positive intracellular expression of P4HA1 at granular cell layer (yellow arrows) (orig. mag.400x).

\section{DISCUSSION}

Diabetes mellitus has been known to have a significant influence on the periodontium and is viewed as a risk factor for both gingivitis and periodontitis. The relationship seems highly dependent upon the level of glycemic control ${ }^{(12)}$.
The current periodontal disease classification lists "diabetes mellitus-associated gingivitis" as a distinct disease entity, although there is no distinct diabetes-associated periodontitis, uncontrolled or poorly controlled DM is considered a modifier of preexisting periodontitis that adjunctively enhances its severity ${ }^{(13)}$.

Rat gingival model used in the present study for testing HA gel effect on gingivitis associated with DM because it is a suitable animal model it is simple, fast and reliable. Periodontal research has favored many animal models of which the rat periodontal model is most popular for studying periodontal pathology ${ }^{(14)}$.

Experimental diabetes mellitus has been induced in laboratory animals by several methods. In the present study experimental DM induced in the experimental groups with a single intraperitoneal dose $(50 \mathrm{mg} / \mathrm{kg})$ of STZ dissolved in citrate buffer $(\mathrm{pH} 4.5)^{(11)}$. Periodontal Disease developed in rats in relation to indigenous plaque, to experimentally introduced microorganisms, or to experimentally introduce bacterial products ${ }^{(14)}$. In the present study ligature were placed around the cervices of the mandibular incisors ${ }^{(18)}$, maxillary second molar, resulting in plaque induced gingivitis, ligatures were checked after application, and the lost were replaced ${ }^{(9)}$.

Topical application of $0.8 \% \mathrm{HA}$ gel was utilized in the present study twice per a day for two weeks and gingival index was recorded at baseline, $1^{\text {st }}$ and $2^{\text {nd }}$ week interval ${ }^{(7)}$.

In the present study P4HA1 marker was used to evaluate in of the effect of hyluronan on plaque induced gingivitis modified with diabetes mellitus, by immunohistochemical analysis of epithelium of gingival specimen. The strong expression of P4HA1 in positive control group as well as in groups without treatment as in group IIa and IIb in the cells of prickle, granular and cornified cell layers may be related to the hyperglycemia in DM which may induces blood flow abnormalities, which further 
enhance tissue hypoxia that play a critical role in regulating P4HAs ${ }^{(15)}$. This mechanism may explain the findings of strong expression of P4HA1 lobserved in the present investigation.

The effect of hypoxia caused by DM and gingivitis in the present study revealed an expression of P4HA1 was in agreement with Chakravarthi et al. (2014) who reported that hypoxia increase the expression of P4HA1\& P4HA2 in breast cancer ${ }^{(16)}$

The effect HA gel $0.8 \%$ on DM associated with gingivitis and on the expression of P4HA1 in the present study was in agreement with Zhu et al.(2015) who reported significantly accelerated healing of rat palatal wound which was related to the decreased effect of hypoxia and reduction in $\mathrm{P} 4 \mathrm{Hs}$ action, by topical application of dimethyloxalylglycine with hyaluronic acid ointment ${ }^{(17)}$

The present study showed a favurable expression of Prolyl 4 hydroxylase in treatment of plaque induced gingivitis modified with DM, using hyaluronan than other included groups.

\section{CONCLUSION}

The topical application of Hyaluronic acid gel improves the clinical gingival conditions in diabetic rat model; also it is effective in treatment of gingivitis associated with diabetes. Prolyl 4 Hydroxylase A1 is useful diagnostic and prognostic marker for periodontal destruction and it is useful in evaluating the effect of different host modulating agents. Hyaluronic acid gel has host modulating effect and has an effect on the expression of Prolyl 4 HydroxylaseA1 evidenced by histological and immunohistochemical analysis.

\section{REFERENCES}

1. Feher E., Gyorffi A., Fazekas A. Neurogenic inflammation of gingivo mucosal tissue in streptozocin -diabetic rat. Archives of Physiology and Biochemistery: 2001; 109(3):230-33.

2. Shlossman M., Knowlerwc, Pettitt D.J., Genco R.J. Type 2diabetes mellitus and periodontal disease. J Am Dent Assoc.1990; 121:532-36.

3. Mealey B.L., Ocampo G.L. Diabetes mellitus and periodontal disease. Periodontal. 2007; 44:127-53.
4. Ramamurthy N.S., Golub L.M. Diabetes increases collagenase activity in extracts of rat gingiva and skin.J Periodontal Res. 1983; 18(1):23-30.

5. Bartold PM. Interleukin (stimulates Proteoglycan and Hyaluronic acid production by human gingival fibroblasts in vitro. Aust Dent J 1988; 33(6):467-75.

6. Gawron K., Lazarz-Bartyzel K., Potempa J., and Chomyszyn-Gajewska M. Gingival fibromatosis: clinical, molecular and therapeutic issues Orphanet J Rare Dis. 2016; 11: 9.

7. Gontiya G., Galgali S.R. Effect of hyaluronan on periodontitis: A clinical and histological study. J Indian SocPeriodontol. 2012; 16:184-92.

8. Chumakova Y., Vishnevskaya A., Kakabadze A., Karalashvili L., Kakabadze Z. Clinical and biochemical analysis of ligature-induced periodontitis in rats. Georgian Med News. 2014 ; (235):63-9.

9. Liu R., BAL H.S., Desta T., Krothapalli N., Alyassi M., Luan Q., Graves. D. Diabetes enhances periodontal bone loss through enhanced resorption and diminished bone formation. JDR. 2006 ; (85):6 510-514.

10. Fu E., Nieh S., Wikesjo U.M. The Effect of Plaque Retention on Cyclosporine-Induced Gingival Overgrowth in Rats. J Periodontol 1997; 68:92-98.

11. Ahmet D., Ela T. F., Ersin U., Şennur K., Muzaffer A. K. Histological investigation of the impact of streptozotocininduced experimental diabetes on the healthy gingivae of rats. Biotechnology \& Biotechnological Equipment. 2014; 28:4,710-715.

12. Moritz A., Mealey B. Periodontal disease, insulin resistance, and diabetes mellitus: a review and clinical implications. Grand Rounds Oral-Sys Med. 2006; 2:13-20.

13. Kuhr A., Popa-Wagner A., Schmoll H., Schwahn C., Kocher T. Observations on experimental marginal periodontitis in rats. J Periodontal Res 2004; 39: 101-106.

14. Shaju P. J., Sonia N. Rat gingival model for testing drugs influencing inflammation. IEJSME. 2013; 7(2): 8-16.

15. Rajhans N.S., Kohad R.M., Chaudhari V.G., Mhaske N.H. A clinical study ofthe relationship between diabetes mellitus and periodontal disease. J Indian Soc Periodontol. 2011; 15(4):388-92.

16. Chakravarthi B.V., Pathi S.S., Goswami M.T., Cieślik M., Zheng H., Nallasivam S., et al. The miR-124-Prolyl Hydroxylase P4HA1-MMP1 axis plays a critical role in prostate cancer progression Oncotarget. 2014; 5(16): 6654-6669.

17. Zhu T., Park H.C., Son K.M., Yang H.C. Effects of dimethyloxalylglycine on wound healing of palatal mucosa in a rat model. BMC Oral Health. 2015; 15: 60. 